\title{
Electronic Waste Recycling Business: Solution, Choice, Survival
}

\author{
Wisakha Phoochinda*, Saraporn Kriyapak \\ Graduate School of Environmental Development Administration, National Institute of Development Administration, Bangkok \\ 10240, Thailand
}

Corresponding Author Email: wisakha.p@nida.ac.th

https://doi.org/10.18280/ijsdp.160409

Received: 20 March 2021

Accepted: 3 June 2021

\section{Keywords:}

waste from electrical and electronic equipment: WEEE, electronic waste, recycle, management, circular economy

\begin{abstract}
This study aimed to investigate factors impacting the electronic waste management in Thailand and recommend guidelines to drive the electronic waste recycling business in the country. The study used the Balanced Scorecard (BSC) as a conceptual framework. The in-depth interview was carried out using the semi-structured interview with the target agencies including government agencies, local administrative organizations, establishments related to electronic waste management (Factories in categories 105 and 106) as well as community junk shops in Chatuchak District, Bangkok. The study findings revealed that in considering the volume of electronic waste generated in Thailand and the share of important basic metals and plastics as components in electrical and electronic equipment to be used as secondary raw materials, the potential value from electronic waste recycling (household electrical appliances) could reach over $9,000,000,000$ baht $(9,165,701,106$ baht) with the increasing trend following the increased volume of electronic waste. The market of the electronic waste recycling business in Thailand had the potential to grow. Upgrading of the electronic waste management system in Thailand was required for more efficiency, in particular, the process of collection, buy-back of product waste, reuse, and increased technological potential. Advanced technology needed to be developed to extract metals from electronic waste in order to obtain more varied metals.
\end{abstract}

\section{INTRODUCTION}

The economic, technological, and industrial development, as well as the expansion of urbanization generate high demand for electrical and electronic equipment, resulting in increased production in line with the demand of consumers and connection with the global economic development. The aforementioned reasons combined with a shorter working life of electrical appliances and a lower rate of repair generate the problems of electronic waste with the volume that exceeds the ability for management. In 2019, the global electronic waste reached 53.6 million metric tons or the average of $7.3 \mathrm{~kg}$ per person. On average, Electrical and Electronic Equipment (EEE) worldwide would increase 2.5 million metric tons a year [1].

Most electronic waste in Thailand comes from the community through household consumption or over $85 \%$ of the total volume of electronic waste. In 2019, Thailand generated 421,335 tons of electronic waste (with the exception of smuggling of illegal electronic waste) or up from 2012 with the volume of electrical and electronic waste of 357,000 tons or the average increase of $2.25 \%$ a year [2]. The major electronic waste in Thailand includes TVs, CRTs, LCDs, refrigerators, washing machines, air conditioners, personal computers, notebooks, and mobile phones [3]. The various components of electronic waste can be utilized with value, such as gold, copper, lead, and nickel. With the correct recycled process, it will reduce the volume of electronic waste and can utilize the usable parts of electronic waste for optimal benefit and at full efficiency in compliance with the Circular
Economy. Therefore, the electronic waste recycling business will assume an important role in electronic waste management.

However, what is important to consider in recycling business operations is that the volume of electronic waste entering the system must be sufficient to allow return on investment. In 2015, according to the Pollution Control Department, most people would sell the unused electronic waste to the business of buying back used items (informal sector) or $51.27 \%$, followed by keeping them $25.32 \%$, disposing them with general waste $15.60 \%$, and giving them away $7.83 \%$ respectively. As a result, the volume of community electronic waste consisted of only $7.1 \%$ of the collected volume to enter the recycling process compared with the total volume of community electronic waste [4]. This was in accordance with the information of Asian countries with the rate of electronic waste recycling of only $11.7 \%$ which was low compared with European countries with the rate of electronic waste recycling as high as $42.5 \%$ [1]

At present, in Thailand, there is no clear and concrete system to promote the reuse of electronic waste. The major factor may be attributable to the absence of law enforcement specifically for electronic waste management. Despite many laws with provisions on management of various types of waste, there is no provision on the enforcement of specific electronic waste management.

Based on the above factors, the researcher took interest in the study of the electronic waste recycling business. As electronic waste in Thailand is still inappropriately managed, recycled materials which are used as alternative raw materials (circular supplies) back to the industrial sector are still small. 
Moreover, the government concretely supports the drive of Circular Economy in the dimension of Bio-Circular-Green Economy (BCG) with "Waste management and efficient use of resources". The electronic waste management driven by the process may answer the needs of electronic waste management in Thailand.

\section{METHODOLOGY}

\subsection{Conceptual framework and key informant}

The study of "Electronic Waste Recycling Business: Solution, Choice, Survival" consisted of qualitative research through a collection of secondary data and in-depth interviews with relevant target groups using the semi-structured interview, main central and local agencies and establishments related to electronic waste management (Factories in categories 105 and 106) as well as junk shops. The conceptual framework of the study is shown in Figure 1.

The situation of the electronic waste recycle business in Thailand was assessed by using the Balance Scorecard composed of effectiveness, electronic waste management, target groups and learning and development. Then the business opportunity of electronic waste management was valued so as to offer the guidelines to drive the electronic waste recycle business in Thailand.

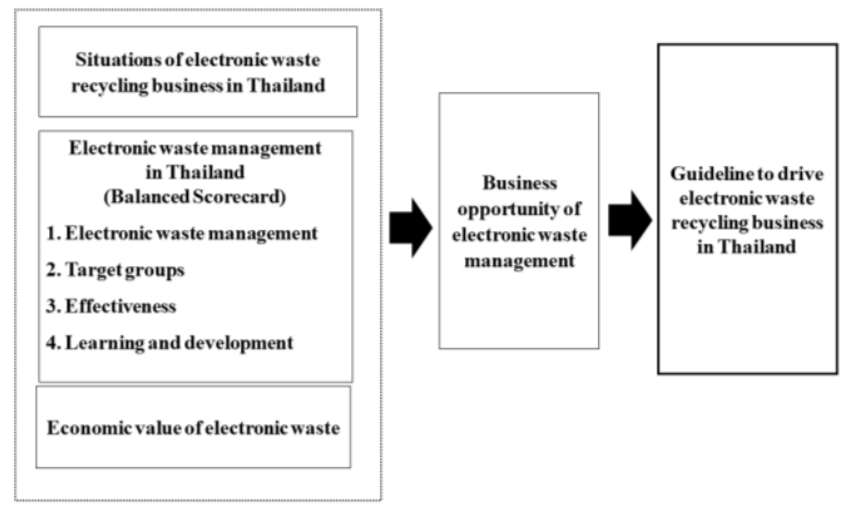

Figure 1. Conceptual framework of the study

\subsection{Data analysis}

The information was analyzed by using content analysis, summary from the in-depth interview and secondary data in four dimensions, namely effectiveness, target group, internal management, and learning and development in order to gain insights into the electronic waste management situations in Thailand.

For the value of electronic waste recycling and the opportunity of the value of alternative raw materials in the industrial sector, the use of secondary data such as the volume of electronic waste generated in Thailand raw materials that could be reused from electrical product waste, as well as raw material prices based on the current market prices were calculated. Good management processes since origin included collecting and sorting a sufficient volume of raw materials to feed them to the recycling system of the industrial sector, using recycling technology, innovation, and extraction of valuable materials from product waste.

Then, the results of the analysis of electronic waste management and the analysis of the economic value of electronic waste were integrated to draw up the guidelines and open up opportunities to drive the electronic waste recycling business in Thailand.

Data obtained from the secondary data and interview with responsible units were verified by the triangulation technique in order to confirm the validity of the results. The authors confirmed this by comparing the results obtained from various responsible units, namely the Pollution Control Department, the local government organization, e- waste recycling businesses, such as Wongpanit International Co., Ltd. and Total Environmental Solution Co., Ltd. in which they have the same and different perspectives in electronic waste management at both local and national levels.

\section{RESEARCH RESULTS}

\subsection{Situations of electronic waste recycling business in Thailand}

As for the origin of electronic waste in organizations such as government buildings, academic institutes, private companies, and industrial plants, the management was conducted through bidding to medium and large electronic waste recycling entrepreneurs. As for household electronic waste, most people would sell unused electronic waste to the business buying back used items or $51.27 \%$ [4]. The business of buying back used items was, therefore, the intermediary between waste-generating consumers and industrial plants using valuable materials from electronic waste for the production into new products. The business of buying back used items served to collect and sort initial community electronic waste or repair second-hand goods for resale. It was considered an important initial process of electronic waste management to sell to various recycling industrial plants. As for the parts that could not be recycled, they would be sent to plants for further waste disposal. The details of the businesses relevant to electronic waste management in Thailand are as follows (Figure 2) [5].

3.1.1 Types and relationships of businesses relevant to electronic waste management

There were sorters of valuable materials, such as those who picked up waste from waste piles, households, and sidecar buyers of used items. There were over 100 communities, which sorted electronic waste in Krabi, Kalasin, Chonburi, Chiang Rai, Chiang Mai, Nakhon Pathom, Nonthaburi, Buriram, Pathum Thani, Prachinburi, Ayutthaya, Ratchaburi, Lamphun, Samut Prakan, Samut Sakhon, Sa Kaeo, Amnat Charoen, and Bangkok [6]. Based on the survey of working situations of population in Q3/2019, it was forecast that the sidecar buyers, those searching for and collecting waste totaled over 114,000 persons across Thailand [7].

Middlemen buying valuable materials included small and medium entrepreneurs, large entrepreneurs or large junk shops with machines and staff who would buy recycled parts from small entrepreneurs and send them to industrial plants. Based on the registration of recycling businesses in 2018, there were 3,102 establishments, mostly companies and small businesses, with 1,246 establishments situated in the central plains or $40.17 \%$, followed by 745 establishments in the east or $24.02 \%$, and 620 establishments in Bangkok or $19.99 \%$ respectively [8]. 


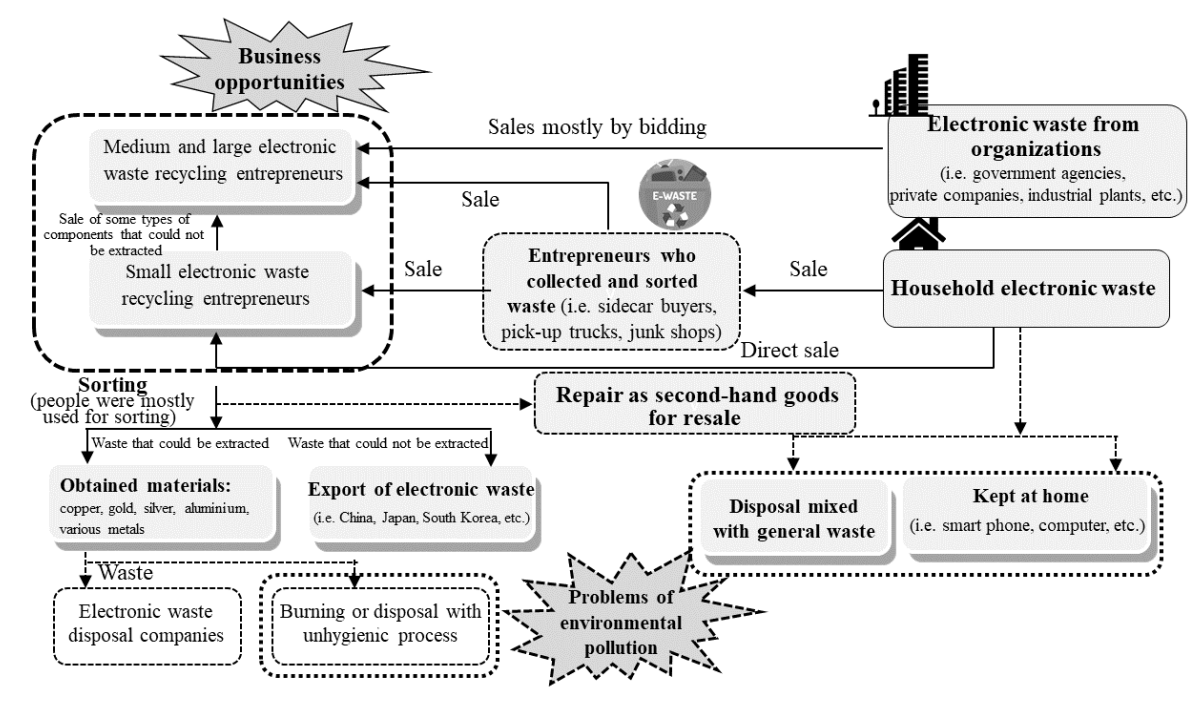

Figure 2. Situations and business opportunities of electronic waste recycling business in Thailand Source. Kasikorn Research Center, [5]

Industrial plants included both Thai and foreign entrepreneurs or joint investors. Some foreign entrepreneurs operated electronic waste recycling businesses in Thailand in the initial management processes, such as sorting, disassembling parts, and exporting them for recycling at parent companies, etc. As for the standard factories for electronic waste recycling in Thailand, their number was limited and not sufficient for electronic waste disposal in each area. In 2018, there were 1,761 industrial plants dealing in electronic waste recycling. They were divided into 1,222 sorting factories/landfills or unused materials and 539 factories producing unused raw materials from industrial products for reuse. In Chonburi, Rayong, and Chachoengsao, there were many such industrial plants [9].

3.1.2 Characteristics and technology of electronic waste recycling entrepreneurs in Thailand

The characteristics of electronic waste management in Thailand in small and medium entrepreneurs consisted of collecting electrical and electronic equipment, disassembling their parts by hand, sorting valuable parts to be sent to material recycling factories, and exporting them for recycling. In this disassembling process, some parts using personal protective tools included gloves or masks. But most processes were not academically correct. Circuit boards from electronic equipment, which were considered cheap, would be collected and sold to merchants who came around in the community before crushing and extracting valuable metals abroad. There were a few domestic entrepreneurs with technology to extract valuable metals from electronic waste. Entrepreneurs in Thailand still did not invest a lot in recycling technology and extraction of valuable metals. There were, therefore, challenges and opportunities to collect and sort community electronic waste, which was an important origin of electronic waste in Thailand. Moreover, the volume of electronic waste in Thailand tended to increase on a continuous basis.

In Thailand, the Recycling Technology Research and Development Center of the Department of Primary Industries and Mines was the first government agency in the country to provide the technology of $\mathrm{R} \& \mathrm{D}$ services in waste recycling. It served as a prototype and transferred knowledge of recycling technology and pollution management to recycling entrepreneurs for academically correct and environmentally- friendly business operations. The center invented the first highly efficient and environmentally-friendly machine to sort metals from the circuit board waste in Thailand. It also served as a prototype in the industrial sector for the optimal use of resources.

\subsection{Electronic waste management in Thailand}

The electronic waste management in Thailand according to the Balanced Scorecard (BSC) under the four dimensions could be summarized from the collection of secondary data and in-depth interviews with main relevant agencies as follows:

\subsubsection{Effectiveness}

In Thailand, the electronic waste that could be collected and entered the system was over $450,000-500,000$ tons a year. However, the appropriate collection to enter the system constituted only $10 \%$ [10]. The major reasons included the following: non-sorting of community hazardous waste from general waste, people's lack of awareness and local administrative organizations' lack of rules and regulations to accommodate the sorting of community electronic waste from general waste, and no law enactment to supervise the private sector responsible for the management of electrical and electronic equipment waste. As for the people sector, they generally disposed of electrical and electronic waste mixed with other types of waste or sold it to sidecar buyers who resold it to shops which would disassemble waste parts despite the fact that it was hazardous waste requiring safe disposal. The parts that could be recycled would be sold. The rest of the waste would be disposed of through outdoor burning as well as dumping in community ponds, causing hazardous substances to leak into the environment. The buy-back system of electronic waste directly from consumers was not concrete as people tended to dispose of the waste with general waste, sell it to merchants who bought back used items or sidecar buyers of used items (informal sector), posing obstacles to collect and sort community waste to enter the recycling process.

If Thailand had efficient electronic waste management, it would constitute an important supporting factor to strengthen the supply chain of electronic waste recycling business in Thailand in the future Figure 3 [11]. The private sector or 
producers must take into account increased costs, including collection and transfer of electronic waste under their brand for sorting and recycling. However, they would receive valuable materials from waste sorting for further benefits or recycling plants might earn revenue from recyclable materials. However, for the non-recyclable materials, there would be costs in sending them to the disposal factories at the final destination. At this point, they were all costs. Finally, it would depend on the market mechanism that would determine and support the process of electronic waste management.

\subsubsection{Electronic waste management}

Thailand has become aware of the importance of electronic waste management since 2004 with the (Draft) Act on the Management of Waste Electrical and Electronic Equipment that the Pollution Control Department expected to put in force in 2021 and integrate WEEE Management Strategy as the operating guidelines by focusing on decentralization to local administrative organizations for hazardous waste management, including electronic waste. In practice, however, household electronic waste was not efficiently collected. It was partly the flow to the informal collection system (informal sector), such as sidecar buyers, junk shops, small entrepreneurs who were community residents and did not register their factories, as well as donation, repair shops, or second-hand shops, etc. As a result, there was incorrect disassembling of parts and extraction of metals from product waste, emitting pollution to the environment and affecting people's health, as well as placing burdens for disposal on local administrative organizations who must bear responsibilities. It was, therefore, crucial to enable sidecar buyers, junk shops, and small entrepreneurs to comply with the laws, regulations, and academic principles so that the buy-back business of used items could operate correctly and become an important mechanism to collect electronic waste out of the ecosystem.

The establishments with a lawfully correct management process would have fewer problems as they had to comply with the regulations and sanitation principles, correct methods of disposal and treatments which must be safe and not impact the environment. Therefore, it can be summarized that the electronic waste management in Thailand depended on the methods of this waste management. If raw materials can be reused and recycled based on the circular economy principle, they need to be managed according to the academic principle. Consumers have to choose electronic products that can be recycled, properly stored, brought into the treatment process, and disposed of in the recycling plant.

\subsubsection{Target groups}

There were a lot of target groups relevant to electronic waste management as follows:

The public sector. Its responsibilities included the enactment of laws and issuance of regulations, system of efficient collection and disposal of electronic waste, guidelines to feed electronic waste into the recycling process and to obtain raw materials that could be reused according to the Circular Economy.

The private sector, producers, and entrepreneurs of recycling business. Their responsibilities included participation in responsibilities towards production and selling products by promoting the buy-back of product waste. Electronic waste disposal plants participated in comprehensive waste management by preparing investment in domestic electronic waste recycling to enable the reuse of domestic resources.

The people and social sectors. They were the major mechanism and factor to drive the electronic waste management as they contributed to waste management since origin, starting from choosing products, repair to reducing waste, sorting, and disposing of product waste in appropriate channels with easy management.

Sidecar buyers and junk shops. In Thailand, the collection of electronic waste was mostly done by the informal sector who served as an intermediary between consumers and business units. They greatly contributed to the collection of electronic waste out of the ecosystem, which was out of the management system of government agencies as well. In this group, some disassembled electrical and electronic parts by hand without protective equipment and with incorrect methods of sorting valuable metals. As a result, many types of heavy metals contaminated the environment. As this group was skillful in disassembling parts, factories did not have to make additional payments which otherwise would have increased their costs. Moreover, the government could not cope with all legal provisions. So, it would be beneficial if this group correctly entered the management system.

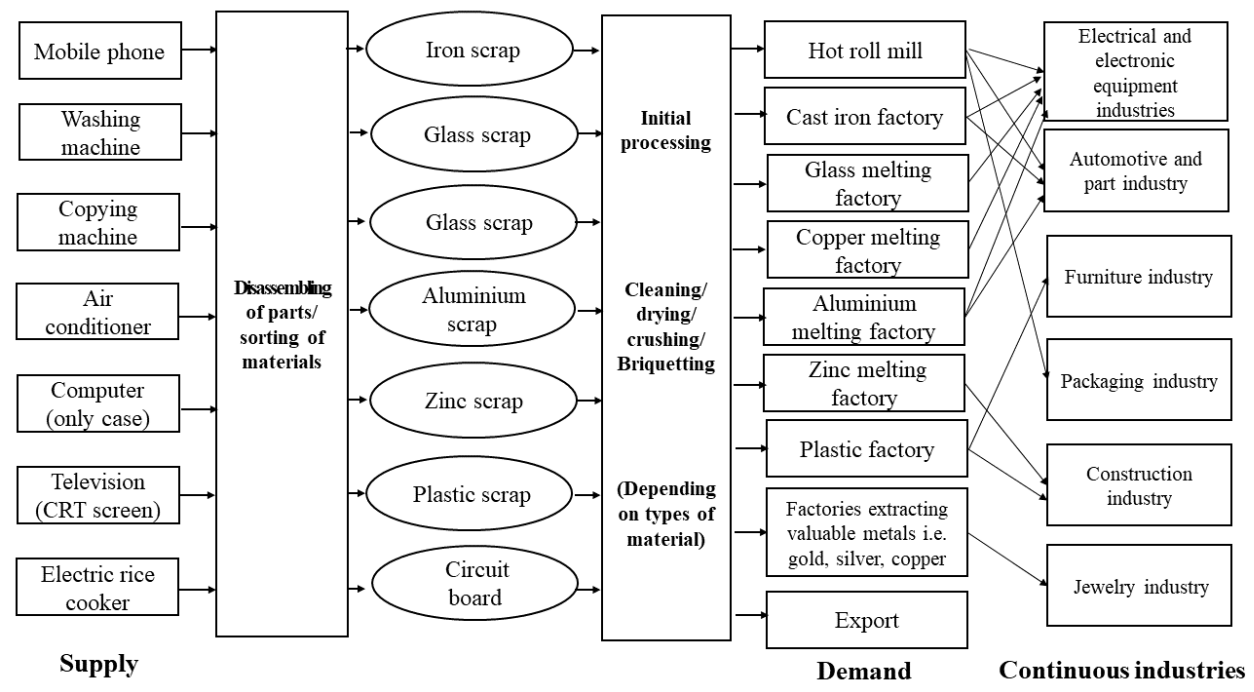

Figure 3. Relationships between recyclable materials and supporting industries Source. Energy and Environmental Engineering Center, [11] 
Table 1. Roles of target groups in electronic waste management

\begin{tabular}{cl}
\hline Target groups & \multicolumn{1}{c}{ Roles } \\
\hline Public sector & $\begin{array}{l}\text { Enactment of laws and formulation of regulations, creation of the system to efficiently } \\
\text { collect and dispose of electronic waste }\end{array}$ \\
\hline $\begin{array}{c}\text { Private sector such as producers, and } \\
\text { entrepreneurs of recycling business }\end{array}$ & $\begin{array}{l}\text { Responsible for produce and sell products, buy-back of product waste, and prepare } \\
\text { investment in electronic waste recycling in the country }\end{array}$ \\
\hline People and social sectors & $\begin{array}{l}\text { Waste management since origin and disposal of product waste through appropriate } \\
\text { channels }\end{array}$ \\
\hline Sidecar buyers and junk shops & $\begin{array}{l}\text { Intermediary between consumers and business units and major groups in collection of } \\
\text { household electronic waste }\end{array}$ \\
\hline
\end{tabular}

Table 1 shows the complementary role of each target group although it lacks efficient tools, such as specific laws on electronic waste management. To upgrade efficient electronic waste management, create business opportunities for electronic waste management, and reuse materials in the industrial system, awareness must be raised for electronic waste management, including an expansion and an increase of business channels of recycled materials in the electronic waste. Cooperation must also be forged between all sectors, including the public, private, people sectors, academic institutes, independent entities, and communities.

For efficient electronic waste management, it required laws or specific government policies as well as awareness and increased responsibilities of producers as major parts in reduction of waste at origin, increased channels to accommodate people to sort hazardous and electronic waste for disposal, increase drop-off points to cover more areas, and carry out efficient and comprehensive operations. Disposal, exchange, or buy-back of product waste could be done at the determined drop-off points in department stores, shopping malls, gas stations, communities, government buildings, academic institutes, etc. Sidecar buyers of used items and junk shops (informal sector) must be correctly developed under the common regulations. There must be a continuous cooperation network between various sectors, and integrated work in electronic waste management at origin, half way, and final destinations. Business opportunities of the electronic waste recycling group would be clearer if electronic waste entered the recycling process in order to correctly reuse the valuable resources. It would reduce import of raw materials and use of the world's limited natural resources for maximum benefit.

\subsubsection{Learning and development}

As for learning and the application of technology and innovation, Thailand had potential through the Recycling Technology Research and Development Center by the Department of Primary Industries and Mines, Ministry of Industry, as the first government agency in Thailand responsible for research to drive waste to become alternative resources in the industrial sector. It invented the first highly efficient and environmentally-friendly machine in Thailand to sort metals from the circuit board waste. The Center also served as a prototype to enable the industrial sector to use resources for maximum benefit. Academic institutes were also ready and interested in the study and research of electronic waste management in the country to achieve maximum efficiency. As for the electronic waste management at origin, it was found that the people sector and the electronic waste management with a lack of knowledge on the part of some sidecar buyers of used items and junk shops posed the obstacles to collect electronic waste to enter the correct management system, impacting the environment and people's health in the long run. Therefore, it was necessary to focus on knowledge development for people as the starting point, then raise awareness of environmental impact and value of electronic waste that could be reused as raw materials in the production process leading to continuous and sustainable practice.

\subsection{Business opportunities for electronic waste management}

\subsubsection{Economic value of electronic waste}

As for the paradigm of the Circular Economy, electronic waste should be considered major secondary sources of raw materials. Electronic waste consisted of metals and plastics that could be used as mineral sources in the industrial sector. Due to the reduced volume of reserved minerals and the shortage of raw materials in the industrial sector, difficulties arose in access to resources, expansion of mining areas in many countries including Thailand as well as the problems of pollution and an increased volume of waste on a continuous basis [12].

Table 2. Prices of major basic metals and plastics used in the calculation of value

\begin{tabular}{ccc}
\hline Types & $\begin{array}{c}\text { Market Prices } \\
\text { (baht/ton) }\end{array}$ & $\begin{array}{c}\text { Market Prices for } \\
\text { materials from } \\
\text { recycling (baht/ton) }\end{array}$ \\
\hline Copper & $240,343.00^{(1)}$ & $168,240.10$ \\
\hline Aluminium & $62,682.00^{(1)}$ & $43,877.40$ \\
\hline Lead & $63,054.00^{(1)}$ & $44,137.80$ \\
\hline Zinc & $87,327.00^{(1)}$ & $61,128.90$ \\
\hline Gold & $1,736,213.55^{(2)}$ & $1,215,349.49$ \\
\hline Iron & $12,845.88^{(3)}$ & $8,992.12$ \\
\hline Plastic & $41,000.00^{(4)}$ & $28,700.00$ \\
\hline Source: (1) London Metal Exchange (LME) [13] \\
(2) Singapore Precious Metals Exchange [14] \\
(3) Iron and Steel Institute of Thailand [15] \\
(4) ABS average prices, Thai Plastic Industries Association [16]
\end{tabular}

The electronic waste generated in urban or community areas was considered "urban mining" due to many valuable and nonvaluable metals which, once recycled, could be used as alternative raw materials. The raw materials in the electronic waste worldwide in 2019 included extracted iron, copper, and gold and valued approximately 57,000 million USD calculated at $17.4 \%$ of electronic waste recycling rate. The emission of carbon dioxide was also reduced to the net 15 million metric tons equaled to the emission of pollution from the recycling of secondary raw materials replacing virgin materials. It was, therefore, crucial to increase the rate of collection and recycling of electronic waste worldwide with the rapid growth expected to reach 74.7 million metric tons by 2030 for recycling to replace old sources of raw materials [1].

In this study, the research team calculated the value from 
the reuse of electronic waste taking into account major basic metals with widespread use, such as iron, aluminium, copper, zinc, lead, and plastics. The electronic product waste used in the calculation included televisions, computers, refrigerators, air conditioners, washing machines, and mobile phones.

According to the Energy and Environmental Engineering Center [11], the average volume of electronic waste as shown in Table 2, and computer, air conditioner, washing machine, and refrigerator wastes contained reusable materials with the share of $97 \%, 96.17 \%, 95.56 \%$, and $87.2 \%$ respectively. Television waste had the lowest share of the reusable materials or $39.46 \%$ (Table 4 ).

The raw materials from recycling have a price lower than usual at approximately $20-30 \%$, thus in this study using the $70 \%$ of Market Prices to calculate (Table 3). The results of the calculation of the value of electronic waste in 2017 revealed that the value from electronic waste recycling (household electric appliances) was over 9,000,000,000 baht
$(9,165,701,106$ baht $)$ (Table 5$)$. It meant that the country could reduce the import of raw materials in the industrial sector by over 9,000,000,000 baht a year. The increasing trend followed the increased volume of electronic waste. The other factors included the market prices of the raw materials, and the processing of materials back to alternative raw materials (secondary raw materials) according to the Circular Economy.

Table 3. Average volume of electronic waste in 2017

\begin{tabular}{cc}
\hline Electrical appliances & $\begin{array}{c}\text { Volume of waste } \\
\text { (tons) }\end{array}$ \\
\hline Television & $98,379.71$ \\
\hline Computer & $56,087.54$ \\
\hline Refrigerator & $63,884.71$ \\
\hline Air conditioner & $75,419.61$ \\
\hline Washing machine & $60,851.64$ \\
\hline Mobile phone & $8,797.58$ \\
\hline Source: (1) The Office of Industrial Economics, [10]
\end{tabular}

Table 4. Share of reusable components in 2017

\begin{tabular}{|c|c|c|c|c|c|c|c|c|}
\hline \multirow{2}{*}{ Electrical appliances } & \multirow{2}{*}{ Share of reusable e waste (wt.\%) } & \multicolumn{7}{|c|}{ Share of reusable components ${ }^{(2)}(\mathrm{wt} . \%)$} \\
\hline & & Iron & Copper & Aluminium & Plastic & Lead & Zinc & Gold \\
\hline Television & 39.5 & 17.9 & 3.0 & 8.8 & 9.9 & - & - & - \\
\hline Computer & 97.0 & 26.9 & 5.6 & 23.9 & 26.0 & 10.8 & 3.7 & 0.1 \\
\hline Refrigerator & 87.2 & 54.5 & 3.4 & 0.3 & 29.1 & - & - & - \\
\hline Air conditioner & 96.2 & 54.4 & 16.5 & 9.4 & 15.9 & - & - & - \\
\hline Washing machine & 95.6 & 50.6 & 3.4 & 0.9 & 40.6 & - & - & - \\
\hline Mobile phone & $61(3)$ & 3.0 & 15.0 & 3.0 & 40.0 & - & - & - \\
\hline
\end{tabular}

Source: (2) Energy and Environmental Engineering Center, [11] (3) Department of Primary Industries and Mines, [17]

Table 5. Potential value of electronic waste in 2017

\begin{tabular}{|c|c|c|c|c|c|c|c|c|}
\hline \multirow{2}{*}{ Electrical appliances } & \multirow{2}{*}{ Volume of reusable waste (MT) } & \multicolumn{7}{|c|}{ Value of electronic waste (MBaht) } \\
\hline & & Iron & Copper & Aluminium & Plastic & Lead & Zinc & Gold \\
\hline Television & 0.04 & 158.0 & 491.6 & 378.1 & 278.7 & - & - & - \\
\hline Computer & 0.05 & 135.7 & 528.4 & 588.2 & 418.5 & 267.4 & 126.9 & 34.1 \\
\hline Refrigerator & 0.06 & 313.0 & 94.2 & 7.0 & 533.7 & - & - & - \\
\hline Air conditioner & 0.07 & 368.9 & 2089.8 & 311.1 & 343.7 & - & - & - \\
\hline Washing machine & 0.06 & 277.1 & 352.2 & 23.5 & 709.1 & - & - & - \\
\hline Mobile phone & 0.01 & 2.4 & 222.0 & 11.6 & 101.0 & - & - & - \\
\hline \multicolumn{9}{|c|}{ Total value 9165.7 million baht } \\
\hline
\end{tabular}

Source: calculated by researchers

3.3.2 Trend of electronic waste recycling market in Thailand

Phacharaphot Nuntramas at Krungthai COMPASS [7] reported that there were 4,500 startups related to waste management business worldwide with 4,500 new startups. Moreover, according to Navigant Research, the market value of smart waste collection using the Internet of Things (IoT) worldwide was forecast to increase to 223 million USD by 2025 or the growth of nearly 4 times from 2016 at 57.6 million USD. This was considered a giant leap compared to the market value of waste management worldwide, expected to grow at the average of $6 \%$ a year. It was also forecast that the intensity of policy implementation of the government's Bio-CircularGreen Economy (BCG), awareness of environmental preservation of all sectors in the world, as well as application of technology in management and production process system of recycling business would be major factors driving the growth of recycling businesses in Thailand at the average of $5.7 \%$ a year in the next 5 years from 170,000 million baht in 2019 to 224,000 million baht in 2024 or approximately $1.2 \%$ of the Gross Domestic Product (GDP).
Moreover, according to Kasikorn Research Center [5], in 2016 the electronic waste recycling market in Thailand was valued at approximately 4,770 million baht. One ton of electronic waste could generate approximately 67,100 baht. In 2017 , the electronic waste recycling market in Thailand was valued at 4,920 - 5,000 million baht or an increase of 3.1 $4.8 \%$ from 2016. It was in line with the expansion of the volume of community electronic waste in Thailand. The report also mentioned that electronic waste consisted of many metals, such as gold, silver, copper, aluminium, etc. These metals could generate the return as high as $6-8$ folds of the costs. The buy-back of electronic waste became a treasure that could generate employment and income to Thai entrepreneurs in the waste recycling business.

Kasikorn Research Center [5] reported that the market value of electronic waste recycling business in Thailand had the opportunity for potential growth in 4 years, and the use of advanced technology to extract more rare and valuable metals. The electronic waste recycling market in Thailand in 2021 is estimated to increase to $10,290-11,420$ million baht or up 
109.1 - 128.3\% from 2017. Kasikorn Research Center [5] also reported that in the future the electronic waste recycling business would have the opportunity for high growth. The potential of growth of the electronic waste recycling business in Thailand should depend on 2 main driving factors, namely upgrading the system of electronic waste management in Thailand for more efficiency and using advanced technology to extract metals from electronic waste to obtain more various metals. However, the Department of Primary Industries and Mines, the Ministry of Industry, sought to develop the technology that could extract valuable metals to be used as alternative resources in line with the Circular Economy. The prototype technology could efficiently extract valuable metals from the PCB circuit boards.

At present, according to the factories classified by industrial types based on economic activities (ISIC) by the Department of Industrial Works [9], there were in total 644 recycling factories type ISIC 3830 with materials recovery. Yet, there were only 110 factories relevant to the recycling of electrical and electronic waste, which was very little compared to the volume of electrical and electronic waste presently generated.

While electronic waste management did not have a comprehensive management system, the appropriate electronic waste management was to sort the types of electronic waste. The damaged parts not yet expired should be repaired for reuse. The expired parts should be sorted by types and disassembled before being processed into raw materials and entering a new production process. The parts that could not be sent through the production process would be sent to the recycling process. The comprehensive operation would continuously reduce the volume of electronic waste. For Thailand, the problems started with an inefficient process of sorting electronic waste without entering the process of electronic waste management since origin, resulting in waste that required sole disposal. At the same time, the process of disposal was not appropriate to electronic waste disposal, resulting in pollution and finally impacting people's health. Therefore, the opportunity to develop technology and business relevant to electronic waste management in Thailand could be developed in each process of electronic waste management.

\section{CONCLUSION}

Impacting factors for electronic waste management included Thailand's lack of basic waste management infrastructure, a sound waste management system as well as legal framework or a clear guideline for electronic waste management. Source separation is not institutionalized, and many areas are left unserved. Thailand has not yet been concerned much about the value of the electronic waste. Electronic waste in Thailand might end up in open dumps or open burning. High-value electronic waste was collected by the informal sector, and they lacked occupational, health and safety training and proper equipment, causing the release of toxic chemicals.

Thailand had opportunities to develop the business and technology of electronic waste recycling. The factors included the volume of electronic waste continuously on the rise, the advancement of recycling technology that could extract valuable metals from electronic waste, the tendency of shortage of raw materials for both valuable and non-valuable metals, such as gold, silver, copper, iron, zinc, to replace mining, the tendency of the growth of waste recycling market, the opportunity to solve the problems of increasing community hazardous waste in the future, and the reuse through the process to become secondary raw materials according to the Circular Economy.

A guideline to drive the electronic waste recycling business in Thailand is that Thailand has to increase higher volume of electronic waste to the recycling process. This was in line with Kasikorn Research Center (2017) who reported that the market value of the electronic waste recycling business in Thailand still had ample room to grow with potential in the future if electronic waste management could be efficiently upgraded with $20 \%$ of community waste collection entering the recycling process compared to the total volume of community electronic waste.

The Department of Primary Industries and Mines (Recycling Technology Research and Development Center) invented and conducted research on various recycling technologies to be ready as prototypes and transferred knowledge to recycling entrepreneurs for operations with academically correct methods. Many establishments were interested and ready to serve as factories for comprehensive extraction and recycling of electronic waste.

The buy-back of product waste still lacked efficiency, causing the insufficient volume of electronic waste for entering the management system and for investing in developing the recycling technology. Waste in the informal sector was collected by sidecar buyers and junk shops (informal sector), which was considered a mechanism in the system to collect household product waste. However, such methods would cause the valuable electrical and electronic waste for recycling to leave the system, and it would be difficult to collect it in sufficient volume to feed the integrated system of electronic waste management that should take place in Thailand. As a result, the public sector lacked motivation in investing in technology and setting up comprehensive plants for sorting and recycling electronic waste. At the same time, Thailand would lose the opportunity to reuse valuable resources from electronic waste in the system. The study revealed that the loss of direct economic value from the loss of income from electronic waste recycling to obtain valuable metals that could be used as raw materials in industrial plants contributed to over 9,000,000 million baht a year.

The recommended guidelines to drive the electronic waste recycling business in Thailand are as follows:

(1) Drive for the enactment of specific laws to collect, recycle, reuse, and correctly manage electronic waste, including the necessary development of guidelines of technological management. Efficient electronic waste management should determine the concept of Extended Producer Responsibility (EPR) in parallel with the concept of Polluter Pay Principle (PPP) and the concept of Circular Economy for endless reuse of electronic waste.

(2) Support the transfer of technology and appropriate methods of electronic waste management, technology of electronic waste recycling to entrepreneurs as well as processes, laws, and regulations accommodating businesses, concretely driving technology and innovation of recycling for concrete commercialization, development of platforms and application of waste recycling businesses that can follow the flow of each type of waste.

(3) Set up a system to collect electronic product and equipment waste. For the electronic waste recycling business, the volume of the raw materials entering the system must be sufficient to generate economic value and stimulate additional 
investments from the private sector as well as increase the channels for development of the second-hand market.

(4) Introduce financial measures and tax mechanisms to stimulate the private sector. To use the market mechanisms for the electronic waste recycling business, the government needs to accelerate the design of the electronic waste management fund to create the mechanism and the cycle to collect electronic waste.

(5) Strengthen the potential of sidecar buyers, buyers of used items (informal sector) with specific skills in collecting and sorting such items. However, there still lacks support for academic knowledge and budget. The government's promotion and upgrading are the necessary and important mechanisms for the formal electronic waste management. Registration should also cover informal sidecar buyers and junk shop owners for them to receive necessary supporting factors from the government.

\section{REFERENCES}

[1] Forti, V., Balde, C.P., Kuehr, R., Bel, G. (2020). The global E-waste monitor 2020 quantities, flows and the circular economy potential. United Nations University (UNU)/United Nations Institute for Training and Research (UNITAR) - co-hosted SCYCLE Programme, International Telecommunication Union (ITU) and International Solid Waste Association (ISWA), Bonn/Geneva/Rotterdam.

[2] Pollution Control Department. (2020). Thailand Pollution Situation 2019, Bangkok: Ministry of Natural Resources and Environment.

[3] Pollution Control Department. (n.d.). Handbook for waste management of electrical and electronic products, Bangkok: Ministry of Natural Resources and Environment, Bangkok, Thailand.

[4] Pollution Control Department. (2015). Integrated Waste Electrical and Electronic Products Management Strategy 2015 - 2021, Ministry of Natural Resources and Environment, Bangkok, Thailand.

[5] Kasikorn Research Center. (2017). E-waste ... a treasure trove of waste recycling businesses. http://www.newsdatatoday.com/images/News/OO1-917/580.pdf, accessed on July 16, 2020.

[6] Wittayaanumas, S (2017). Electronic Waste
Management in Thailand. TDRI Report No. 133. https: //tdri.or.th/wp-conte nt / uploads / 2018/04 / wb133 .pdf. accessed on July 16, 2020.

[7] Nantaramat, P., et al. (2020). How to throw away (waste) Create opportunities from waste with a recycling platform.

https://krungthai.com/Download/economyresources/Eco nomyResourcesDownload 442how to bin final.pdf. accessed on Jan. 6, 2021.

[8] Department of Business Development. (2018). Business registration information. https://www.dbd.go.th /index.php, accessed on Jul. 16, 2020.

[9] Department of Industrial Works. (2020). Factory information. http://www.eeec.eng.ku.ac.th/diw- weee /, accessed on Jan. 6, 2021.

[10] The Office of Industrial Economics. (2020). Guideline Handbook for E-Waste Management within ASEAN and Korea. Regional Workshop: ASEAN-Korea Dialogue for E-Waste Management. Thailand.

[11] The Energy and Environmental Engineering Center. (2014). The Complete Report of the Project for the Establishment of a Life Cycle Tracking System for Electrical and Electronic Equipment. The Energy and Environmental Engineering Center.

[12] Boonyachat, N. (2020). Mechanisms to drive circular economy into the industrial sector. Department of Primary Industries and Mines.

[13] London Metal Exchange. (2020). LME PRICES. https://www.lme.com/, accessed on Dec. 6, 2020.

[14] Singapore Precious Metals Exchange. (2020). Gold \& Silver Prices. https://sgpmx.com/, accessed on Dec. 6, 2020.

[15] Iron and Steel Institute of Thailand. (2020). News. https://news.isit.or.th:8080/isit/, accessed on Dec. 6, 2020.

[16] Thai Plastic Industry Association. (2020). Average price of ABS plastic. https://www.tpia.org/index.php/statisticreport/plasticpricereport, accessed on Dec. 6, 2020.

[17] Department of Primary Industries and Mines. (2013). Handbook of Alternative Resource Wastes. (Household group). Under the waste accounting scheme for renewable resources, fiscal year 2555. Copyright owner Department of Primary Industries and Mines. Ministry of Industry. 